\title{
Incorporating feasibility and collaboration into large-scale planning for regional recovery of coral reef fisheries
}

\author{
Kendall R. Jones ${ }^{1,2,3,8, *}$, Joseph M. Maina ${ }^{2,4}$, Salit Kark ${ }^{2,5}$, Timothy R. McClanahan ${ }^{6}$, \\ Carissa J. Klein ${ }^{1}$, Maria Beger ${ }^{2,7}$ \\ ${ }^{1}$ School of Earth and Environmental Sciences, University of Queensland, St Lucia, QLD 4072, Australia \\ ${ }^{2}$ Centre for Conservation and Biodiversity Science, School of Biological Sciences, University of Queensland, St. Lucia, \\ QLD 4072, Australia \\ ${ }^{3}$ Wildlife Conservation Society, Global Conservation Program, Bronx, NY 10460, USA \\ ${ }^{4}$ Department of Environmental Sciences, Macquarie University, North Ryde, NSW 2109, Australia \\ ${ }^{5}$ The Biodiversity Research Group, School of Biological Sciences, University of Queensland, St Lucia, QLD 4072, Australia \\ ${ }^{6}$ Wildlife Conservation Society, Marine Programs, Bronx, NY 10460, USA \\ ${ }^{7}$ School of Biology, Faculty of Biological Sciences, University of Leeds, Leeds LS2 9JT, UK \\ ${ }^{8}$ Present address: School of Earth and Environmental Sciences, University of Queensland, St Lucia, \\ QLD 4072, Australia
}

\begin{abstract}
Broad-scale overharvesting of fish is one of the major drivers of marine biodiversity loss and poverty, particularly in countries with high dependence on coral reefs. Given the heterogeneity of fishing effort and management success, and the scarcity of management resources, it is necessary to identify broad-scale locations for promoting successful fisheries management and conservation. Here, we assessed how fisheries management and conservation priorities in the Western Indian Ocean would change if the objectives were to (1) minimize lost fishing opportunity, (2) minimize the time for fish biomass to recover, (3) avoid locations of low management feasibility based on historical management outcomes, and (4) incorporate international collaboration to optimize the rate for achieving goals. When prioritizing for rapid recovery of fish biomass rather than minimizing lost fishing opportunity, we found that the area of priority management zones changed by over $60 \%$ in some countries. When locations of low management feasibility were avoided, the recovery time of fish biomass across the region increased 4 -fold. International collaborations prioritized management zones in remote, high biomass, and low fishing pressure reefs and reduced the recovery time of fish 5-fold compared to non-collaboration scenarios. Thus, many of these conservation objectives favored wealthy and sparsely populated over poorer and natural resource dependent countries. Consequently, this study shows how prioritization policies, incentives, decisions, and conflicts will produce highly variable outcomes and challenges for sustainability.
\end{abstract}

KEY WORDS: Africa $\cdot$ Conservation planning · Marine and fisheries policy $\cdot$ Marxan $\cdot$ Indian Ocean $\cdot$ Sustainable fisheries

\section{INTRODUCTION}

Coral reef fisheries are harvested beyond sustainable levels in many regions, which is often linked to loss of biodiversity and ecosystem functions (Dulvy et al. 2004, Bellwood et al. 2011, McClanahan et al.

${ }^{*}$ Corresponding author: k.jones10@uq.edu.au
2011, Mora et al. 2011). Local fishery management, along with reduction of regional and global drivers of degradation, is imperative for recovery of reefs and sustainable fisheries (Hughes et al. 2010, Graham et al. 2013). Prioritizing locations for restrictions on fisheries or marine protected areas (MPAs) by utilizing

() The authors 2018. Open Access under Creative Commons by Attribution Licence. Use, distribution and reproduction are unrestricted. Authors and original publication must be credited. 
marine spatial planning methods is expected to improve fisheries and the services provided by marine ecosystems (Fernandes et al. 2005, Gaines et al. 2010). However, planning less frequently considers the outcomes of different priorities, assumptions, incentives, decisions, and consequences of large-scale collaboration histories, instead aiming to minimize the adverse impacts of conservation plans on fisheries (Ban \& Klein 2009, Metcalfe et al. 2015).

While fisheries policies and management actions propose to achieve sustainable fisheries, the lack of clear and scaled metrics of success has led to poor planning in many cases (Worm et al. 2009). One useful metric is reef fish biomass, because it is easily measured and is associated with predictable declines in ecological states, processes, and ecosystem services (McClanahan et al. 2011, Pereira et al. 2013, Karr et al. 2015, MacNeil et al. 2015). Therefore, reef biomass is an integrative metric that can be used for setting management objectives with clear ecological thresholds (McClanahan 2018). For example, in the Western Indian Ocean (WIO), maximum sustainable fisheries yield and ecological health occurs when total reef biomass is between 300 and $600 \mathrm{~kg} \mathrm{ha}^{-1}$ (McClanahan et al. 2011). Conservation areas, where all ecological processes are maintained, should have a biomass of $\sim 1150 \mathrm{~kg} \mathrm{ha}^{-1}$ in the WIO (McClanahan et al. 2015). Consequently, biomass thresholds and recovery rates can inform spatial prioritization objectives (McClanahan et al. 2016).

Increasing agreement and compliance with management plans should be a primary objective when developing sustainable fisheries policies (MacNeil et al. 2015, McClanahan et al. 2016). Therefore, there is a need to consider how socioeconomic and political characteristics influence the likelihood of achieving strong compliance (hereafter referred to as 'management feasibility') (Mascia 2003, McClanahan et al. 2016). The factors influencing management feasibility are diverse, and include strength of governance (Ostrom 2007), perceptions of management legitimacy (McClanahan \& Abunge 2016), and willingness of management entities to collaborate (Knight et al. 2010). While some maps of feasibility have been developed across a variety of spatial scales (O'Connor et al. 2003, Knight et al. 2010, Mills et al. 2013), it is rarely considered in spatial prioritization (Polasky 2008, Mills et al. 2013). By making feasibility a constraint in spatial prioritization, the risk of inappropriate placement and compliance failures is minimized.

International collaboration is also important in sociopolitically complex regions where conflicts occur on borders and management resources are scarce, such as the WIO (Cordner 2010, Bueger 2013, Kark et al.
2015). Collaboration, when successful, has been shown to substantially reduce the cost and area required for managing terrestrial and marine environments (Kark et al. 2009, Mazor et al. 2013). Management costs and effectiveness vary across the WIO and collaboration has the potential to reduce shared costs to achieve desired outcomes, such as maintaining fish populations. Transboundary conservation, for example, has been identified as a regional priority between Kenya, Tanzania, and Mozambique to reap potential benefits of collaboration (Nairobi Convention 2015).

By explicitly incorporating management feasibility and international collaboration into management objectives, we built on previous spatial prioritizations using fish biomass recovery information (McClanahan et al. 2016). First, we assessed how using fish biomass recovery changed the spatial distribution of fishery management priority zones compared to the common zoning method of minimizing lost fishing opportunity. Second, we tested the influence of management feasibility on regional management priorities with a feasibility index using measures of fish biomass uncertainty, effectiveness of existing management, and estimates of collaboration potential between WIO countries. Finally, we explored potential socio-politically relevant scenarios of international collaboration to consider how collaboration can improve fish biomass recovery goals.

\section{MATERIALS AND METHODS}

The study area covered the mapped coral reefs in the large region of Kenya to South Africa, and east to the Maldives and Chagos. A previous study developed a $2.5 \mathrm{~km}^{2}$ grid of fish biomass model based on a publicly available map (Reefs at Risk: www.wri.org/ourwork/project/reefs-risk) and 7 predictor variables and their interactions (McClanahan et al. 2016). Variables were those known to influence the large-scale distributions of fish, and included strictness of management, compliance with management, the presence of fishing, distance to markets and market population, and 3 measures of sea surface temperature (Cinner et al. 2016). It is important to note that a limitation of this model is its inability to incorporate smaller scale local influences, such as benthic cover. While detailed benthic cover data would have been informative, data are only available for a small sub-section of the WIO (Maina et al. 2015), so could not be included. Time-torecovery maps were developed using fish biomass recovery rates $\left(\mathrm{kg} \mathrm{yr}^{-1}\right)$ to thresholds for sustainable fishing (450 kg ha ${ }^{-1}$ ) and for conservation areas 
(1150 kg ha ${ }^{-1}$ ). McClanahan et al. (2011) based these thresholds on the fact that maximum sustained fishing yield in the WIO occurs between 300 and $600 \mathrm{~kg} \mathrm{ha}^{-1}$ and selected the sustainable fishing threshold as the mid-range estimate for sustainable fishing production (450 kg ha ${ }^{-1}$ ). They also used a conservation threshold of $1150 \mathrm{~kg} \mathrm{ha}^{-1}$ because below this level is where the first measured changes in ecological processes (e.g. carnivory and herbivory) begin to appear. For full methodological details on fish biomass modeling and biomass thresholds, see McClanahan et al. (2016).

\section{Spatial prioritization for reef fishery management}

We used the conservation prioritization software Marxan with Zones (Watts et al. 2009) to identify priority areas for fisheries management. Marxan with Zones uses a simulated annealing algorithm to determine sets of sites that fulfill pre-determined quantitative targets for biodiversity features while minimizing cost, and also allows for the selection of different management zones (Watts et al. 2009), such as conservation zones or sustainable fishing areas. The cost values used in Marxan with Zones can reflect actual monetary costs (e.g. land purchase price), or any other value that is desirable to minimize (e.g. lost fishing opportunity). We used the $2.5 \mathrm{~km}^{2}$ grid from the fish biomass model as a planning unit, and used the area of the World Conservation Monitoring Centre (WCMC) coral reef distribution (UNEP-WCMC et al. 2010) in each planning unit as a biodiversity feature. We explored questions using different prioritization objectives, but for all objectives we set targets (i.e. proportion of reef in a zone) to include $50 \%$ of reef area in sustainable fishing zones and $20 \%$ in conservation zones, while accounting for existing high compliance fishery closures (McClanahan et al. 2016). We conducted 10 Marxan with Zones runs of 100 repetitions for each objective, producing 10 'best solution' outputs for each objective. The 'best solution' output is the reserve system that performs best at reaching its feature targets with minimal cost. To map Marxan with Zones results, we considered a planning unit to be selected as a conservation or sustainable fishing zone if it was selected in 8 of the 10 'best solution' outputs. Using these base methods, we analyzed 3 spatial prioritization objectives - fishing opportunity baseline, time-to-recovery, and management feasibilitywhich differed only in the values used to be minimized by Marxan with Zones (see Table S1 in the Supplement at www.int-res.com/articles/suppl/m604 p211_supp.pdf for a summary of objectives).

\section{Fishing opportunity baseline objective}

Our baseline spatial prioritization objective used estimates of artisanal fishing landings as the value to be minimized in Marxan with Zones. Minimizing lost fishing opportunity is a common approach in spatial prioritization analyses (Klein et al. 2010, Grantham et al. 2013, Mazor et al. 2013), and we hereafter refer to this objective as the fishing opportunity baseline objective. Fish landing estimates were taken from Halpern et al. (2008), which modeled fish landings from national FAO small-scale fisheries statistics; the data are freely available (doi:10.5063/F19Z92TW). These data give approximate annual artisanal fishing catch at a $1 \mathrm{~km}^{2}$ resolution. As our planning units were $2.5 \mathrm{~km}^{2}$, we used the average artisanal fishing catch within each planning unit as the value to be minimized in Marxan with Zones. Because the artisanal fishing data did not cover remote islands and atolls, we assigned planning units without artisanal fishing data the lowest quartile value of artisanal fishing estimates for the region. Therefore, the Marxan with Zones algorithm ensured that conservation and sustainable fisheries zones contained at least 20 and $50 \%$ of coral reef in the WIO, respectively, while minimizing the amount of lost opportunity for artisanal fishing due to the placement of management zones.

\section{Time-to-recovery objective}

Our second spatial prioritization objective followed McClanahan et al. (2016) by using Marxan with Zones to minimize fish biomass recovery time (hereafter the time-to-recovery objective). Compared to the fishing opportunity baseline objective, this substitutes fish biomass recovery time for artisanal fishing catch as the value to be minimized. Thus, our time-to-recovery for the sustainable fishing zone reflects how long it takes for fish biomass to recover to $450 \mathrm{~kg} \mathrm{ha}^{-1}$. Similarly, the time-to-recovery value for the conservation zone reflects how long it would take for biomass to recover to $1150 \mathrm{~kg} \mathrm{ha}^{-1}$.

\section{Management feasibility objective}

To examine the impacts of incorporating management feasibility, we used the following equation to create a feasibility score $(F)$ that represented the raw time-to-recovery values used in the fish biomass recovery objective, weighted by a measure of manage- 
ment feasibility (hereafter the management feasibility objective). $F$ was used as the value to be minimized in Marxan with Zones, and was calculated using the following equation (see Figs. S1 \& S2 in the Supplement for maps of $F$ values):

$$
F_{i(i=1 \ldots n)}=T_{i}\left(E_{i}+C_{1}+R_{i}\right)
$$

where $T_{i}$ represents the time-to-recovery (in years) of coral reef in planning unit $i$, and $n$ is the total number of planning units. E represents the percentage of successfully managed MPAs in a country, and was taken from Rocliffe et al. (2014) for all countries and territories except Bassas Da India, British Indian Ocean Territory, Glorioso, Ile Europa, Ile Tromelin, and the Maldives, which were assigned $E$ from Reefs at Risk Revisited (Burke et al. 2011). These values were then normalized between 0 and 100 using a fuzzy logic linearly decreasing membership function. $E$ was included because new management activities are likely to be more feasible in areas where current management practices are successful.

$C$ represents the potential for collaboration between countries, and was calculated by normalizing country-level collaboration scores from Levin et al. (2018) between 0 and 100 using a fuzzy logic linearly decreasing membership function and spatially assigning these country scores to planning units. These collaboration scores were derived using linkages between nations based on biodiversity (number of shared species), trade (import/export value between countries), governance (number of shared environmental agreements), and spatial location (geographic relationship) (Levin et al. 2018). We used Thiessen polygons (Thiessen 1911) to determine the nearest exclusive economic zone (EEZ) boundary for each planning unit, and assigned planning units the collaboration score for the 2 countries that share boundaries (Fig. S3 in the Supplement). For example, a planning unit where the closest EEZ boundary is between Kenya and Tanzania would receive the $C$ value for Kenya-Tanzania collaboration. Areas of high collaborative potential may be more feasible for management when considering cross-boundary collaboration, especially for reefs located between 2 countries or territories (Levin et al. 2018).

$R_{i}$ represents a measure of model over-estimation of fish biomass recovery time for planning unit $i$, and is computed from the residuals of the biomass prediction model. To calculate $R$, we used the predicted biomass at upper and lower 95\% confidence intervals (CI) from McClanahan et al. (2016) to calculate time-to-recovery. This allowed us to produce optimistic estimates of time-to-recovery (i.e. from using upper CI) and conservative estimates of time-torecovery (i.e. from using lower $\mathrm{CI}$ ). We then computed $R$ as the ratio of conservative time-to-recovery estimates (lower CI) and optimistic time-to-recovery estimates (upper CI), from the mean predictions of biomass recovery time (taken from McClanahan et al. 2016). These values were then normalized between 0 and 100 using a fuzzy logic linearly decreasing membership function. Our feasibility metric penalizes areas where optimistic biomass predictions (upper CI) are further from mean predictions than conservative biomass predictions (lower CI), because modeled fish biomass in these areas is more likely to be overestimated than underestimated. We included variable $R$ to penalize areas where biomass overestimation is more likely than underestimation, because if biomass is overestimated the actual time-to-recovery for that area will be longer than anticipated. In the reverse situation, time-to-recovery will be underestimated and management activities will be required for a shorter time than anticipated.

\section{Cross-boundary collaboration scenarios}

To investigate the role of cross-boundary collaboration in spatial management prioritization, we allocated planning units to countries or regions using EEZs (e.g. Kenya, Glorioso Islands). We compared 3 international collaboration scenarios, sensu Kark et al. (2009) and Mazor et al. (2013). These were (1) full collaboration scenario with all countries collaborating; (2) partial collaboration scenario, where countries that are currently part of conservation/environmental management agreements collaborate; and (3) no collaboration scenario, where each country acted in isolation. For the partial collaboration scenario we used 2 groups of collaborating countries: Kenya and Tanzania, who have identified transnational collaboration as a regional priority as per the recent convention of parties (COP8) of the Nairobi convention (Nairobi Convention 2015), and members of the Indian Ocean Commission (Comoros, Madagascar, Mauritius, Seychelles and Réunion; Commission de l'Océan Indien 2011).

\section{Comparing prioritization objectives and collaboration scenarios}

To compare management priorities under the (1) fishing opportunity baseline, (2) time-to-recovery, and (3) management feasibility objectives, we calcu- 
lated the area of sustainable fishing and conservation zones under each objective within each country. We also compared the spatial arrangement of selected areas under each objective. Finally, we calculated the Fleiss' Kappa statistic (Fleiss 1971) to summarize the difference in selection frequency across all planning units, where 1 indicates that the combination of planning units selected is identical under each objective, and 0 indicates that all scenarios are distinct. To examine the role of international collaboration scenarios, we compared the area and spatial arrangement of priority areas in each country with respect to the 3 levels of collaboration, under both the time-torecovery and feasibility objectives.

\section{RESULTS}

\section{Comparison of objectives}

Management priorities set under the time-torecovery and management feasibility objectives differed markedly from the fishing opportunity baseline objective that aimed to minimize lost fishing opportunity within management zones. Conservation zones were $50 \%$ larger in the fishing opportunity baseline objective compared to the time-to-recovery objective, whereas the area of sustainable fishing zones was similar across all objectives (Table 1). The time required for fish biomass to recover in conservation zones was 13 times lower under the time-to-recovery objective than the fishing opportunity baseline, with similar reductions seen for sustainable fishing zones (Table 1). Average time-to-recovery increased 6-fold for conservation zones under the management feasibility objective compared to the time-to-recovery objective, but sustainable fishing zones had similar biomass recovery times (Table 1 ).

When comparing the time-to-recovery and management feasibility objectives to the lost fishing opportunity baseline objective, the area of manage-

Table 1. Average time-to-recovery $\left(T_{\mathrm{r}}\right)$ and number of planning units (PUs) selected in conservation and sustainable fishing zones identified under 3 different prioritization objectives

\begin{tabular}{|c|c|c|c|c|}
\hline \multirow[t]{2}{*}{ Prioritization objective } & \multicolumn{2}{|c|}{ Conservation zones } & \multicolumn{2}{|c|}{ Sustainable fishing zones } \\
\hline & $\begin{array}{c}T_{\mathrm{r}} \\
\text { (yr) }\end{array}$ & $\begin{array}{c}\text { No. of } \\
\text { PUs selected }\end{array}$ & $\begin{array}{c}T_{\mathrm{r}} \\
(\mathrm{yr})\end{array}$ & $\begin{array}{c}\text { No. of } \\
\text { PUs selected }\end{array}$ \\
\hline Time-to-recovery & 0.7 & 1702 & 0.5 & 4574 \\
\hline Management feasibility & 4.2 & 3371 & 0.7 & 3816 \\
\hline Fishing opportunity baseline & 9.4 & 3436 & 2.0 & 4904 \\
\hline
\end{tabular}

ment zones within individual countries differed by up to $51 \%$ for conservation zones (Fig. 1a) and $62 \%$ for sustainable fishing zones (Fig. 1b). For example, the Seychelles had $42 \%$ more area included in conservation zones under the time-to-recovery objective compared to the fishing opportunity baseline objective. Conversely, Mozambique had 15\% less area included in sustainable fishing zones under the timeto-recovery objective compared to the fishing opportunity baseline objective (Fig. 1b). These results reflect the fact that Seychelles has high fish biomass levels and is thus a high priority under the time-torecovery objective, whereas fish biomass in Mozambique is much lower due to high levels of fishing. Incorporating management feasibility also resulted in considerable differences with the time-to-recovery objective. For example, Madagascar had 15\% more reef area included in sustainable fishing zones under the management feasibility objective compared to the time-to-recovery objective, while Tanzania had $18 \%$ less (Fig. 1b). A number of countries showed very small differences between all objectives, such as Kenya and Mauritius (Fig. 1a,b).

Broad priority areas for management zones remained similar under both the time-to-recovery and management feasibility objectives, with conservation priorities concentrated in the Seychelles, Maldives, and Chagos (Fig. 2). However, there were differences within countries for both the spatial arrangement and total area of management zones (Fig. 3). For example, reefs in the central Maldives were assigned a much higher priority under the time-torecovery objective, whereas reefs in the north and south were high priorities under the management feasibility objective. Some areas of northern Madagascar became more important under the time-torecovery objective (Fig. 3), despite Madagascar overall having $21 \%$ less reef area in sustainable fishing zones under this objective. Similar spatial differences were seen between the time-to-recovery objective and the fishing opportunity baseline, and between the management feasibility objective and the fishing opportunity baseline (Figs. S4 \& S5 in the Supplement). When comparing across all objectives, the Fleiss' Kappa statistic was 0.25 and 0.47 for sustainable fishing and conservation zones respectively, indicating a low level of similarity between objectives (Table S2 in the Supplement). 

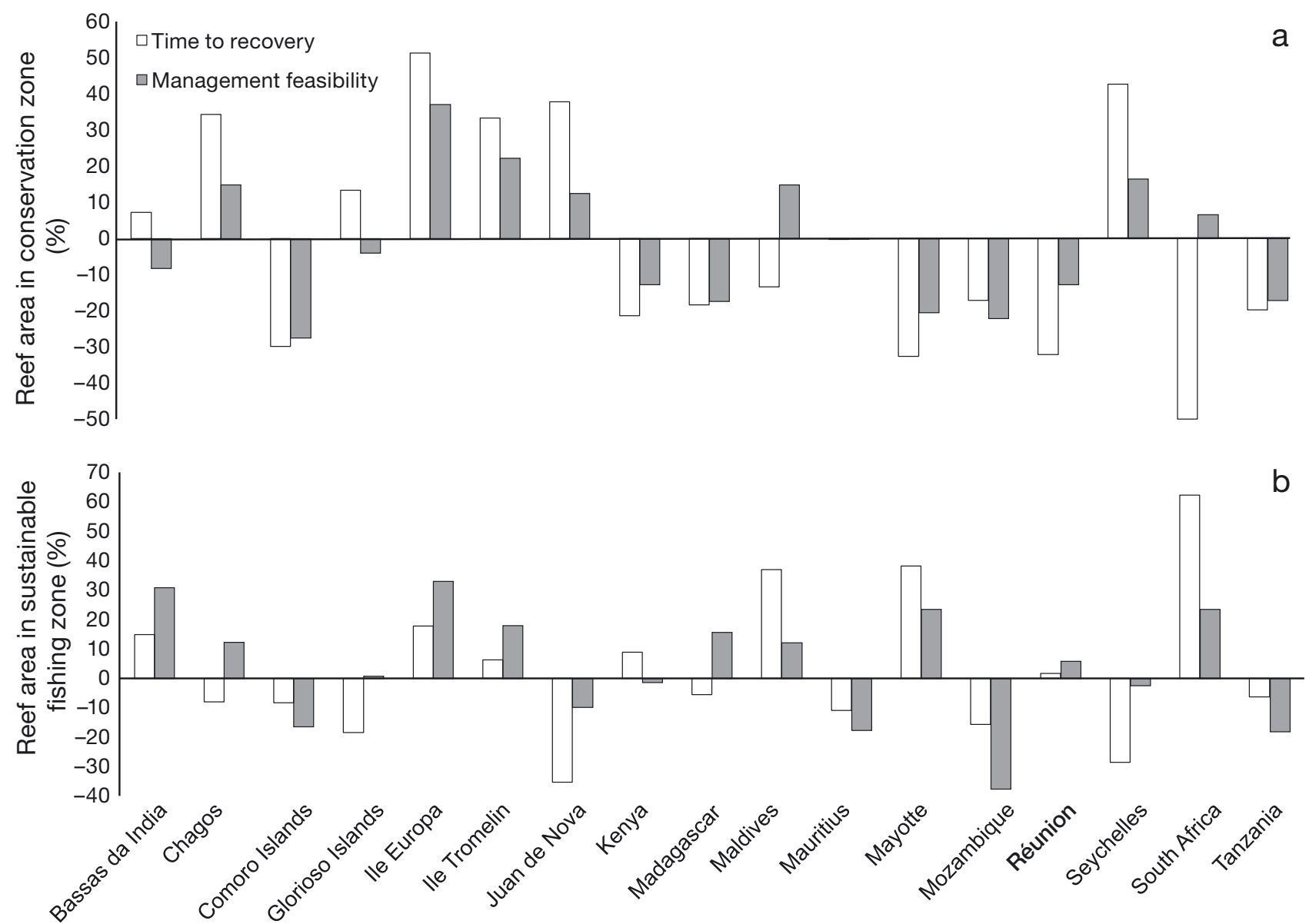

Fig. 1. Average difference from fishing opportunity baseline objective for (a) conservation zones and (b) sustainable fishing zones, expressed as reef area included in conservation and sustainable fishing zones, for priorities identified under the time-to-recovery objective (white) and the management feasibility objective (grey). Conservation zones and sustainable fishing zones contain 20 and $50 \%$ of total Western Indian Ocean (WIO) reef area, respectively. Values are the average of 10 'best solution' outputs from Marxan with Zones

\section{Cross-boundary collaboration priorities}

Cross-boundary collaboration reduced overall timeto-recovery and the area of management zones by redistributing management priorities toward island nations with high fish biomass, such as the Seychelles and Chagos. Results were similar under both time-torecovery and management feasibility objectives, so here we report on the results of the time-to-recovery objective. Under a no collaboration scenario, the time required for fish biomass recovery was increased 5.4 times in conservation zones, and 3.4 times in sustainable fishing zones compared to the full collaboration scenario (Table 2). The partial collaboration scenario reduced recovery time by $37 \%$ in conservation zones, and over $150 \%$ for sustainable fishing zones (Table 2). A full collaboration scenario also required around $21 \%$ less area for conservation zones, and $38 \%$ less for sustainable fishing zones compared to a scenario without collaboration (Table 2).

Collaboration substantially changed the location of management priorities, concentrating priorities in remote locations with high fish biomass (Fig. 4). For example, Chagos had $62 \%$ of its reef contained in conservation zones under a full collaboration scenario, but only $24 \%$ under a partial collaboration scenario (Fig. 4b). Conversely, Réunion had only $13 \%$ of its reef contained in sustainable fishing zones under full collaboration, but this rose to $51 \%$ under the no collaboration scenarios (Fig. 4a). In some nations, the effect of collaboration had contrasting effects for conservation zones and sustainable fishing zones. The Seychelles contained around $30 \%$ more reef in conservation zones under both collaboration scenarios, but around $20 \%$ less reef within sustainable fishing zones (Fig. 4). 


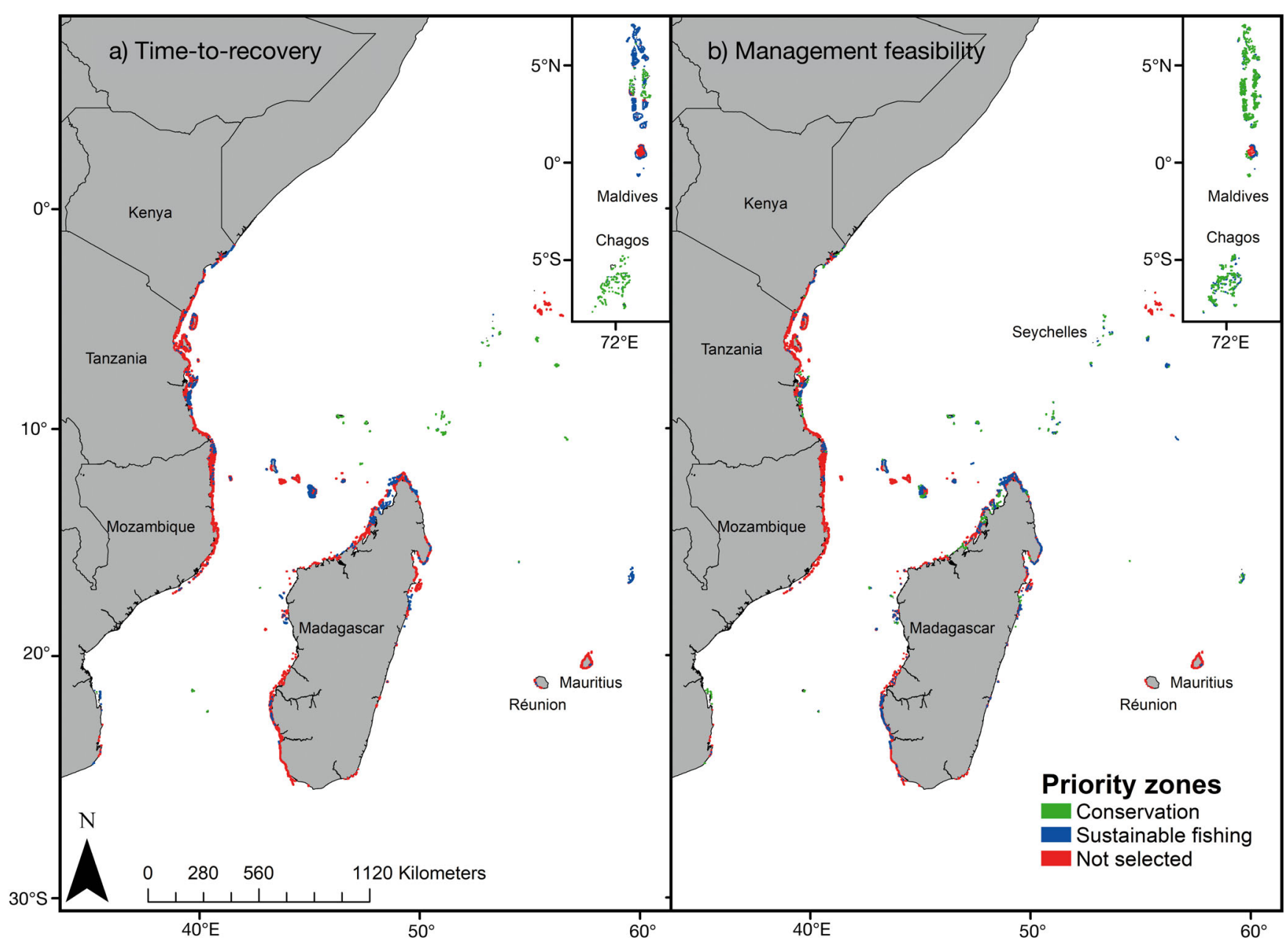

Fig. 2. Priority areas (selected in $>80 \%$ of Marxan with Zones runs) for conservation and sustainable fishing zones from 10 'best solution' Marxan with Zones outputs: (a) priorities identified to minimize the time required for fish biomass recovery to sustainable fishing (450 kg ha ${ }^{-1}$ ) and conservation (1150 kg ha ${ }^{-1}$ ) thresholds (time-to-recovery objective). (b) Priorities identified to minimize time-to-recovery and avoid areas of low management feasibility (management feasibility objective). Each scenario contains $20 \%$ of the total reef area as conservation zones, and $50 \%$ as sustainable fishing zones. This figure is available in high resolution at www.int-res.com/articles/suppl/m604p211_Fig2.png

\section{DISCUSSION}

Incorporating management feasibility and fish biomass recovery into spatial prioritization considerably changed the spatial arrangement of priority locations compared to the baseline, where lost fishing opportunity was the main consideration. Furthermore, the time required for fish biomass to recover increased substantially when avoiding zoning locations of low management feasibility. These increases were attributable to management zones being shifted from infeasible high biomass reefs to lower biomass areas with greater feasibility. Consequently, incorporating management feasibility into spatial prioritizations can help avoid spending resources where effective management seems unlikely (Mills et al. 2013).
Clearly, managing fisheries for socio-economic goals such as food and income is important, but conservation may be challenging and expensive if feasibility is not addressed first (Hicks 2011, McClanahan \& Abunge 2016).

Fishery closures or MPAs often face considerable opposition from fishers, and the imposition of MPAs or other fishery management policies, such as gear restrictions or catch quotas, is unlikely to succeed without broad consensus and community support (Jameson et al. 2002, Beger et al. 2004, McClanahan et al. 2005, FAO 2006, Kamat 2014). Providing information on the length of time required for management to meet demonstrable ecological targets and incorporating fish biomass recovery into management planning should increase knowledge and gain sup- 


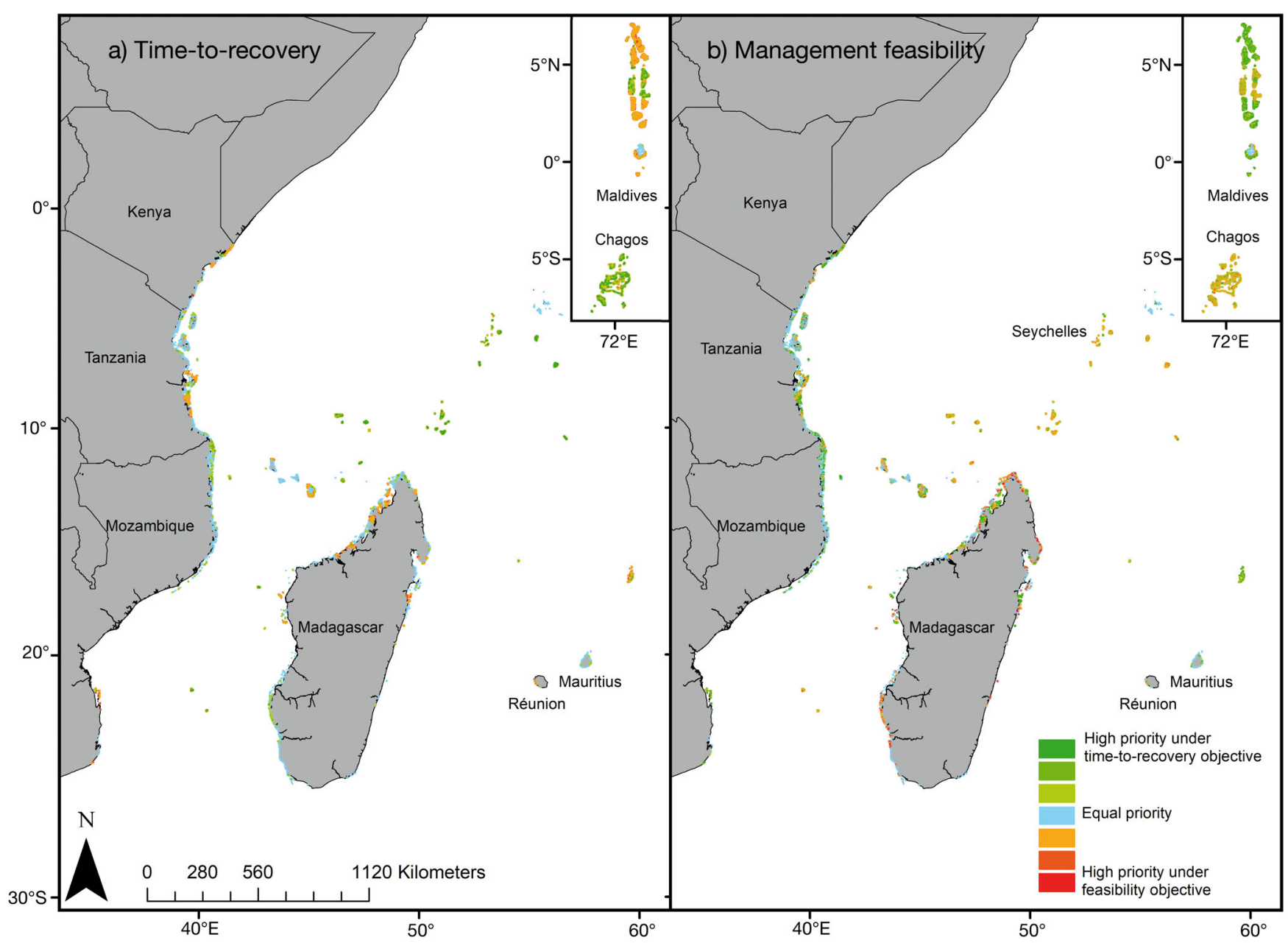

Fig. 3. Difference in planning unit selection frequency for (a) conservation zones, and (b) sustainable fishing zones under timeto-recovery and management feasibility objectives. Planning units are blue if they had equal selection frequencies under both objectives. This figure is available in high resolution at www.int-res.com/articles/suppl/m604p211_Fig3.png

Table 2. Average time-to-recovery $\left(T_{\mathrm{r}}\right)$ and number of planning units (PUs) selected in conservation and sustainable fishing zones identified under 3 different scenarios of international collaboration

\begin{tabular}{|c|c|c|c|c|}
\hline \multirow{2}{*}{$\begin{array}{l}\text { International } \\
\text { collaboration }\end{array}$} & \multicolumn{2}{|c|}{ Conservation zones } & \multicolumn{2}{|c|}{ Sustainable fishing zones } \\
\hline & $\begin{array}{c}T_{\mathrm{r}} \\
(\mathrm{yr})\end{array}$ & $\begin{array}{c}\text { No. of } \\
\text { PUs selected }\end{array}$ & $\begin{array}{c}T_{\mathrm{r}} \\
\text { (yr) }\end{array}$ & $\begin{array}{c}\text { No. of } \\
\text { PUs selected }\end{array}$ \\
\hline Full & 0.7 & 1702 & 0.5 & 4574 \\
\hline Partial & 2.4 & 1632 & 0.7 & 4468 \\
\hline None & 3.8 & 2128 & 1.7 & 7267 \\
\hline
\end{tabular}

port from stakeholders. Where many people are highly dependent on coral reefs for food and income, such as the WIO (Donner \& Potere 2007), stakeholder perceptions and participation are critical to avoiding compliance failures (Graham et al. 2007, Levy 2010, McClanahan 2010).
International collaborations decrease costs of conservation and fishery management efforts but result in management zones being asymmetrically distributed (Table 2, Fig. 4). Fully collaborative conservation plans lead to some countries being exempt from conservation zones (e.g. South Africa, Réunion), while others face additional management responsibilities (e.g. Seychelles). As such, the efficiencies gained by collaboration must be balanced with social equity considerations (Kark et al. 2009, 2015, Halpern et al. 2013). Other spatial prioritization analyses came to similar conclusions for the WIO (Maina et al. 2015, McClanahan et al. 2016) and other marine regions (Kark et al. 2009, Mazor et al. 2013, Beger et al. 2015). Consequently, any gains achieved through regional collaboration will also need to balance considerations of 


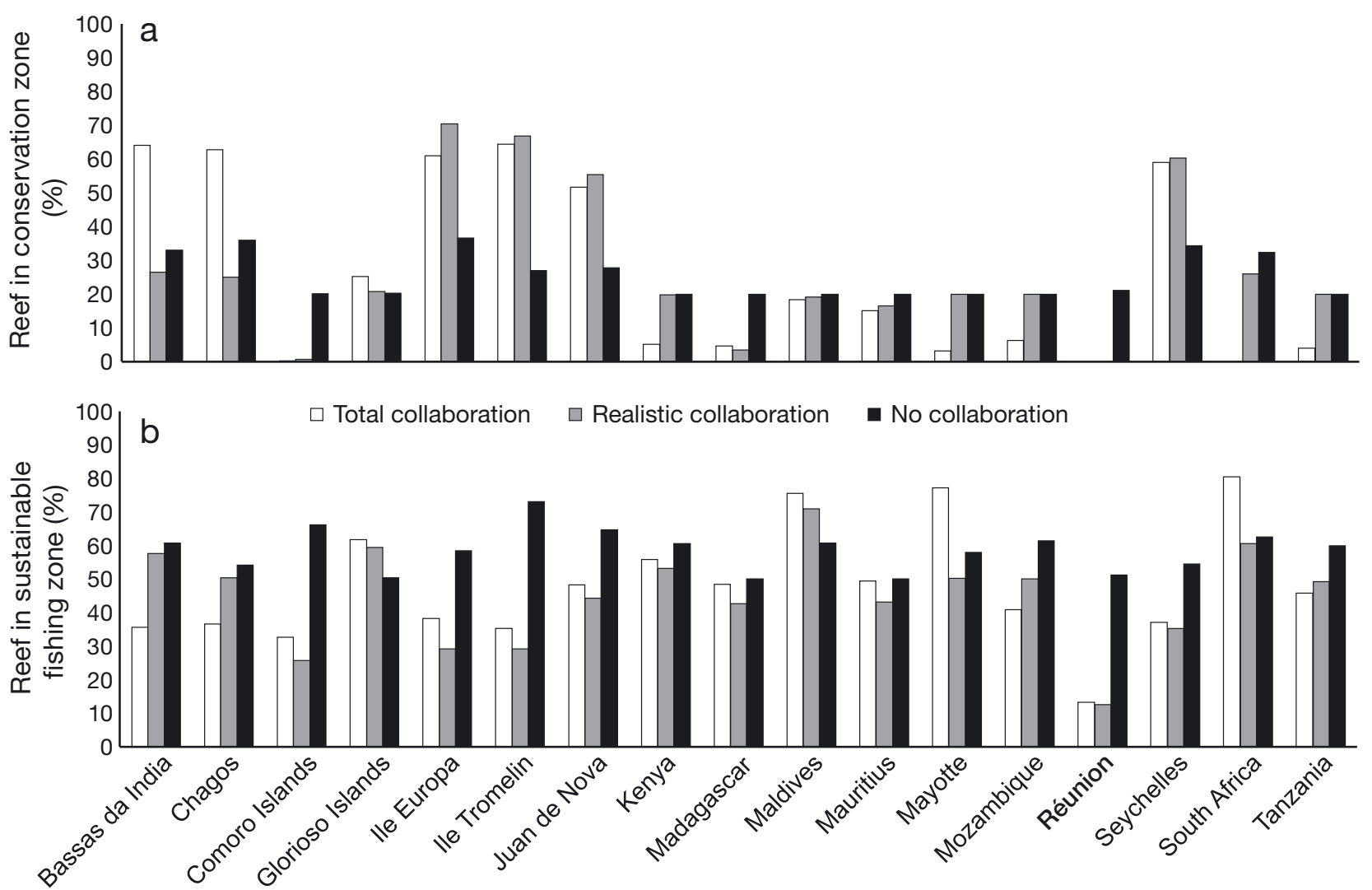

Fig. 4. Percentage of reef of each country contained in priority areas identified under 3 international collaboration scenarios, under time-to-recovery objective. Percentage of reef in each country contained in (a) conservation zones and (b) sustainable fishing zones. Values are the average of 10 'best solution' outputs from Marxan with Zones

sharing costs and responsibilities equitably. Among the many considerations of collaborative natural resource management are the broader suite of economic, political, and social barriers that influence implementation decisions (Sandwith et al. 2001).

The prioritization approach used here favors protecting high biomass areas, which essentially triages low biomass sites. Protecting high biomass is one of a number of goals of management and therefore alternative, and possibly a portfolio of, goals and zoning approaches should be considered. For example, McClanahan et al. (2016) proposed prioritizing the recovery of severely degraded reefs and the surrounding reefs. Another approach not mentioned here is to consider larval dispersal in spatial prioritizations to promote population recovery and persistence (Beger et al. 2010, 2015, Krueck et al. 2017, Álvarez-Romero et al. 2018, Magris et al. 2018). Depending on spatial scales, future work should consider using larval dispersal models (Treml et al. 2008, Kool et al. 2011) or genetic measures (Selkoe \& Toonen 2011, Beger et al. 2014) to represent the larval connectivity within MPA networks. Given the empirical needs and computation complexity of larval dispersal information, simpler approaches for informing MPA placement will be useful (e.g. minimizing distance between MPAs and fishing grounds; Krueck et al. 2017), although this does not discount the need for future research on incorporating larval dispersal into spatial prioritization, as the latter has been shown to influence priorities considerably (Magris et al. 2016). Including the costs of various management options, such as fisheries closures versus gear restrictions, has also been shown to substantially alter management priorities (Ban et al. 2011, McGowan et al. 2018). Furthermore, while total fish biomass is a useful holistic metric of reef function, it does not consider the different recovery rates of fish that are important for recovery of reef function (MacNeil et al. 2015, Martin et al. 2017). Consequently, future research priorities should include (1) combining spatial prioritization approaches to identify areas that overlap under multiple objectives (Allnutt et al. 2012), and (2) considering differential recovery rates and ecological functions of fish (McClanahan et al. 2015).

The data and estimates of management feasibility used here have a number of limitations. Firstly, we 
used only one conservation feature - the area of coral reef per planning unit. While unlikely to change our main conclusions, incorporating better data on species' distributions or biogeographical habitats, along with other conservation objectives (e.g. achieving representation) would likely alter the location of management priorities (Allnutt et al. 2012). Secondly, while our analyses were conducted at a broad spatial scale, the size of fisheries closures in the WIO is relatively small and compliance in these closures is mainly a local scale issue. Local scale studies which build upon our analysis could add important nuances to fisheries management plans. Thirdly, the management feasibility metric used here is dependent on national-level data and could be improved by incorporating more local scale assessments. Management feasibility is influenced by several factors not captured in our metric, including human values and perceptions, as well as economic, ecological, and technical issues (Salomon et al. 2011, Pascoe et al. 2014, McClanahan \& Abunge 2016). Future studies should also consider the ability of local authorities to effectively enforce fishery closures, and the existence and competency of interacting governance networks (Nagendra \& Ostrom 2012, Morrison 2017). Finally, perceptions of fishing restrictions and potential willingness to comply with regulations is known to vary considerably within and between WIO countries (Daw et al. 2012, McClanahan \& Abunge 2016). Data on the perception of fishing restrictions by local communities could be used to assess the likelihood of compliance with fisheries closures/restrictions, thereby improving future management feasibility metrics.

There are also a number of limitations with the artisanal fishing data used in the fishing opportunity baseline objective, although they are the only highresolution artisanal fishing data available across the entire WIO. These data use coastal population and distance-to-land to spatially model the small-scale distribution of national-scale catches (Halpern et al. 2008). This likely overestimates fishing catch on reefs near populated coastal ports, especially when fish landings at these ports reflect fishing effort from a large surrounding area. While artisanal fishing is notoriously difficult to estimate (Zeller et al. 2006, Halpern et al. 2008), incorporating local-scale data on landings at specific ports would help to avoid overestimation around densely populated areas. Furthermore, the artisanal fishing data does not discern between fisheries (e.g. reef fisheries, pelagic/offshore fisheries), and so reef fishing pressure is likely overestimated in places such as the Maldives, where fishers often target pelagic species (Hemmings et al.
2014). This will unduly reduce their selection by the Marxan with Zones objective function aiming to minimize cost. Consequently, incorporating data on catches of specific fish taxa (e.g. Watson 2017) could refine estimates of artisanal fishing to ensure they capture reef fishing effort specifically.

This study demonstrates how incorporating fish biomass recovery, management feasibility, and international collaboration affects fishery management priorities in the WIO - favoring remote and lightly fished regions. We also show that incorporating management feasibility redistributes priorities to wealthier nations or to those with histories of more effective management. Both outcomes result in an uneven distribution of management priorities, and may further burden people in poorer countries where effective fishery management is badly needed to promote food security. It is clear that for spatial prioritization analyses to be useful and incorporated into decision making, many possible values, incentives, scenarios, and metrics must be considered (Allnutt et al. 2012, McClanahan et al. 2016).

Acknowledgements. Support for the data collection and study was provided by the Western Indian Ocean Marine Science Association-Marine Science for Management Program (WIOMSA-MASMA) and the John D. and Catherine T. MacArthur Foundation. The Wildlife Conservation Society, through grants from the John D. and Catherine T. MacArthur Foundation and Australian Research Council (ARC) Center of Excellence for Environmental Decisions (CEED) supported the spatial modeling aspects of the study. S.K. was supported by the ARC, and M.B. was supported by Marie Skłodowska-Curie Fellowship 747102. Members of the ARC CEED working group on the Indian Ocean, including N. Levin and J. Watson, are thanked for promoting an interest in, and discussions around marine conservation planning in the Indian Ocean.

\section{LITERATURE CITED}

Allnutt TF, McClanahan TR, Andréfouët S, Baker M and others (2012) Comparison of marine spatial planning methods in Madagascar demonstrates value of alternative approaches. PLOS ONE 7:e28969

Álvarez-Romero JG, Munguía-Vega A, Beger M, del Mar Mancha-Cisneros M and others (2018) Designing connected marine reserves in the face of global warming. Glob Change Biol 24:e671-e691

Ban NC, Klein CJ (2009) Spatial socioeconomic data as a cost in systematic marine conservation planning. Conserv Lett 2:206-215

* Ban NC, Adams V, Pressey RL, Hicks J (2011) Promise and problems for estimating management costs of marine protected areas. Conserv Lett 4:241-252

* Beger M, Harborne AR, Dacles TP, Solandt JL, Ledesma GL (2004) A framework of lessons learned from communitybased marine reserves and its effectiveness in guiding a 
new coastal management initiative in the Philippines. Environ Manage 34:786-801

Beger M, Linke S, Watts M, Game E, Treml E, Ball I, Possingham HP (2010) Incorporating asymmetric connectivity into spatial decision making for conservation. Conserv Lett 3:359-368

Beger M, Selkoe KA, Treml E, Barber PH and others (2014) Evolving coral reef conservation with genetic information. Bull Mar Sci 90:159-185

Beger M, McGowan J, Treml EA, Green AL and others (2015) Integrating regional conservation priorities for multiple objectives into national policy. Nat Commun 6:8208

Bellwood DR, Hoey AS, Hughes TP (2011) Human activity selectively impacts the ecosystem roles of parrotfishes on coral reefs. Proc R Soc B 279:1621-1629

Bueger C (2013) Communities of security practice at work? The emerging African maritime security regime. Afr Secur 6:297-316

Burke L, Reytar K, Spalding M, Perry AL (2011) Reefs at risk revisited. World Resources Institute, Washington, DC

Cinner JE, Huchery C, MacNeill MA, Graham NAJ and others (2016) Bright spots among the world's coral reefs. Nature 535:416-419

Commission de l'Océan Indien (2011) Smart Fish. Les pays membres de la COI. http://commissionoceanindien.org/ membres/

* Cordner L (2010) Rethinking maritime security in the Indian Ocean Region. J Indian Ocean Reg 6:67-85

NDaw TM, Cinner JE, McClanahan TR, Brown K, Stead SM, Graham NAJ, Maina J (2012) To fish or not to fish: factors at multiple scales affecting artisanal fishers' readiness to exit a declining fishery. PLOS ONE 7:e31460

Donner SD, Potere D (2007) The inequity of the global threat to coral reefs. Bioscience 57:214-215

*Dulvy NK, Freckleton RP, Polunin NVC (2004) Coral reef cascades and the indirect effects of predator removal by exploitation. Ecol Lett 7:410-416

FAO (2006) Report and documentation of the expert workshop on marine protected areas and fisheries management: review of issues and considerations. Food and Agriculture Organization of the United Nations, Rome

Fernandes L, Day JON, Lewis A, Slegers S and others (2005) Establishing representative no-take areas in the Great Barrier Reef: large-scale implementation of theory on marine protected areas. Conserv Biol 19:1733-1744

Fleiss JL (1971) Measuring nominal scale agreement among many raters. Psychol Bull 76:378-382

* Gaines SD, White C, Carr MH, Palumbi SR (2010) Designing marine reserve networks for both conservation and fisheries management. Proc Natl Acad Sci USA 107: 18286-18293

* Graham N, Ferro RST, Karp WA, MacMullen P (2007) Fishing practice, gear design, and the ecosystem approach three case studies demonstrating the effect of management strategy on gear selectivity and discards. ICES J Mar Sci 64:744-750

* Graham NA, Bellwood DR, Cinner JE, Hughes TP, Norström AV, Nyström M (2013) Managing resilience to reverse phase shifts in coral reefs. Front Ecol Environ 11:541-548

* Grantham HS, Agostini VN, Wilson J, Mangubhai S and others (2013) A comparison of zoning analyses to inform the planning of a marine protected area network in Raja Ampat, Indonesia. Mar Policy 38:184-194

Halpern BS, Walbridge S, Selkoe KA, Kappel CV and others (2008) A global map of human impact on marine ecosys- tems. Science 319:948-952

* Halpern BS, Klein CJ, Brown CJ, Beger M and others (2013) Achieving the triple bottom line in the face of inherent trade-offs among social equity, economic return, and conservation. Proc Natl Acad Sci USA 110:6229-6234 r

Hemmings M, Harper S, Zeller D (2014) Reconstruction of total marine catches for the Maldives: 1950-2010. In: Zylich K, Zeller D, Ang M, Pauly D (eds) Fisheries catch reconstructions: islands, Part IV. Fisheries Centre, University of British Columbia, Vancouver

Hicks CC (2011) How do we value our reefs? Risks and tradeoffs across scales in 'biomass-based' economies. Coast Manage 39:358-376

* Hughes TP, Graham NAJ, Jackson JBC, Mumby PJ, Steneck RS (2010) Rising to the challenge of sustaining coral reef resilience. Trends Ecol Evol 25:633-642

* Jameson SC, Tupper MH, Ridley JM (2002) The three screen doors: Can marine 'protected' areas be effective? Mar Pollut Bull 44:1177-1183

Kamat V (2014) 'The ocean is our farm': marine conservation, food insecurity, and social suffering in southeastern Tanzania. Hum Organ 73:289-298

Kark S, Levin N, Grantham HS, Possingham HP (2009) Between-country collaboration and consideration of costs increase conservation planning efficiency in the Mediterranean Basin. Proc Natl Acad Sci USA 106:15368-15373

Kark S, Tulloch A, Gordon A, Mazor T, Bunnefeld N, Levin $N$ (2015) Cross-boundary collaboration: key to the conservation puzzle. Curr Opin Environ Sustain 12:12-24

Karr KA, Fujita R, Halpern BS, Kappel CV and others (2015) Thresholds in Caribbean coral reefs: implications for ecosystem-based fishery management. J Appl Ecol 52: 402-412

Klein CJ, Ban NC, Halpern BS, Beger M and others (2010) Prioritizing land and sea conservation investments to protect coral reefs. PLOS ONE 5:e12431

Knight AT, Cowling RM, Difford M, Campbell BM (2010) Mapping human and social dimensions of conservation opportunity for the scheduling of conservation action on private land. Conserv Biol 24:1348-1358

Kool JT, Paris CB, Barber PH, Cowen RK (2011) Connectivity and the development of population genetic structure in Indo-West Pacific coral reef communities. Glob Ecol Biogeogr 20:695-706

KKrueck NC, Ahmadia GN, Possingham HP, Riginos C, Treml EA, Mumby PJ (2017) Marine reserve targets to sustain and rebuild unregulated fisheries. PLOS Biol 15:e2000537

* Levin N, Beger M, Maina J, McClanahan T, Kark S (2018) Evaluating the potential for transboundary management of marine biodiversity in the Western Indian Ocean. Australas J Environ Manage 25:62-85

KLevy S (2010) Catch shares management. Bioscience 60: 780-785

MacNeil MA, Graham NAJ, Cinner JE, Wilson SK and others (2015) Recovery potential of the world's coral reef fishes. Nature 520:341-344

Magris RA, Treml EA, Pressey RL, Weeks R (2016) Integrating multiple species connectivity and habitat quality into conservation planning for coral reefs. Ecography 39: 649-664

Magris RA, Andrello M, Pressey RL, Mouillot D, Dalongeville A, Jacobi MN, Manel S (2018) Biologically representative and well-connected marine reserves enhance biodiversity persistence in conservation planning. Conserv Lett 11:e12439 
Maina JM, Jones KR, Hicks CC, McClanahan TR, Watson JEM, Tuda AO, Andréfouët S (2015) Designing climateresilient marine protected area networks by combining remotely sensed coral reef habitat with coastal multi-use maps. Remote Sens 7:16571-16587

Martin TSH, Connolly RM, Olds AD, Ceccarelli DM, Fenner DE, Schlacher TA, Beger M (2017) Subsistence harvesting by a small community does not substantially compromise coral reef fish assemblages. ICES J Mar Sci 74: 2191-2200

Mascia MB (2003) The human dimension of coral reef marine protected areas: recent social science research and its policy implications. Conserv Biol 17:630-632

Mazor T, Possingham HP, Kark S (2013) Collaboration among countries in marine conservation can achieve substantial efficiencies. Divers Distrib 19:1380-1393

McClanahan TR (2010) Effects of fisheries closures and gear restrictions on fishing income in a Kenyan coral reef. Conserv Biol 24:1519-1528

McClanahan TR (2018) Multicriteria estimates of coral reef fishery sustainability. Fish Fish 19:807-820

* McClanahan TR, Abunge CA (2016) Perceptions of fishing access restrictions and the disparity of benefits among stakeholder communities and nations of south-eastern Africa. Fish Fish 17:417-437

McClanahan T, Davies J, Maina J (2005) Factors influencing resource users and managers' perceptions towards marine protected area management in Kenya. Environ Conserv 32:42-49

McClanahan TR, Graham NAJ, MacNeil MA, Muthiga NA, Cinner JE, Bruggemann JH, Wilson SK (2011) Critical thresholds and tangible targets for ecosystem-based management of coral reef fisheries. Proc Natl Acad Sci USA 108:17230-17233

* McClanahan TR, Graham NAJ, MacNeil MA, Cinner JE (2015) Biomass based targets and the management of multispecies coral reef fisheries. Conserv Biol 29:409-417

McClanahan TR, Maina JM, Graham NAJ, Jones KR (2016) Modeling reef fish biomass, recovery potential, and management priorities in the Western Indian Ocean. PLOS ONE 11:e0154585

McGowan J, Bode M, Holden $\mathrm{MH}$, Davis $\mathrm{K}$ and others (2018) Ocean zoning within a sparing versus sharing framework. Theor Ecol 11:245-254

Metcalfe K, Vas S, Engelhard GH, Villanueva MC, Smith RJ, Mackinson S (2015) Evaluating conservation and fisheries management strategies by linking spatial prioritization software and ecosystem and fisheries modelling tools. J Appl Ecol 52:665-674

Mills M, Pressey RL, Ban NC, Foale S, Aswani S, Knight AT (2013) Understanding characteristics that define the feasibility of conservation actions in a common pool marine resource governance system. Conserv Lett 6:418-429

Mora C, Aburto-Oropeza O, Ayala Bocos A, Ayotte PM and others (2011) Global human footprint on the linkage between biodiversity and ecosystem functioning in reef fishes. PLOS Biol 9:e1000606

Morrison TH (2017) Evolving polycentric governance of the Great Barrier Reef. Proc Natl Acad Sci USA 114:

Editorial responsibility: Simonetta Fraschetti, Salento, Italy
E3013-E3021

Nagendra H, Ostrom E (2012) Polycentric governance of multifunctional forested landscapes. Int J Commons 6: $104-133$

Nairobi Convention (2015) The eighth conference of the parties to the Nairobi Convention for the protection, management and development of the marine and coastal environment of the Western Indian Ocean (Nairobi Convention), Mahe, Seychelles. https://www.unenvironment. org/nairobiconvention/eighth-conference-parties-nairobiconvention

* O'Connor C, Marvier M, Kareiva P (2003) Biological vs. social, economic and political priority-setting in conservation. Ecol Lett 6:706-711

Ostrom E (2007) A diagnostic approach for going beyond panaceas. Proc Natl Acad Sci USA 104:15181-15187

*Pascoe S, Brooks K, Cannard T, Dichmont CM, Jebreen E, Schirmer J, Triantafillos L (2014) Social objectives of fisheries management: What are managers' priorities? Ocean Coast Manage 98:1-10

Pereira HM, Ferrier S, Walters M, Geller GN and others (2013) Essential biodiversity variables. Science 339: 277-278

Polasky S (2008) Why conservation planning needs socioeconomic data. Proc Natl Acad Sci USA 105:6505-6506

Salomon AK, Gaichas SK, Jensen OP, Agostini VN and others (2011) Bridging the divide between fisheries and marine conservation science. Bull Mar Sci 87:251-274

Sandwith T, Shine C, Hamilton L, Sheppard D (2001) Transboundary protected areas for peace and cooperation. IUCN, Gland

* Selkoe KA, Toonen RJ (2011) Marine connectivity: a new look at pelagic larval duration and genetic metrics of dispersal. Mar Ecol Prog Ser 436:291-305

* Thiessen AH (1911) Precipitation averages for large areas. Mon Weather Rev 39:1082-1089

* Treml EA, Halpin PN, Urban DL, Pratson LF (2008) Modeling population connectivity by ocean currents, a graphtheoretic approach for marine conservation. Landsc Ecol 23:19-36

UNEP-WCMC (United Nations Environment ProgrammeWorld Conservation Monitoring Centre), WorldFish Centre, WRI (World Resources Institute), TNC (The Nature Conservancy) (2010) Global distribution of warm-water coral reefs, compiled from multiple sources including the Millennium Coral Reef Mapping Project. UNEP World Conservation Monitoring Centre, Cambridge

*Watson RA (2017) A database of global marine commercial, small-scale, illegal and unreported fisheries catch 19502014. Sci Data 4:170039

*Watts ME, Ball IR, Stewart RS, Klein CJ and others (2009) Marxan with Zones: software for optimal conservation based land- and sea-use zoning. Environ Model Softw 24:1513-1521

*Worm B, Hilborn R, Baum JK, Branch TA and others (2009) Rebuilding global fisheries. Science 325:578-585

* Zeller D, Booth S, Craig P, Pauly D (2006) Reconstruction of coral reef fisheries catches in American Samoa, 19502002. Coral Reefs 25:144-152

Submitted: December 22, 2017; Accepted: September 3, 2018 Proofs received from author(s): September 24, 2018 